\title{
Teatro ídish argentino (1930-1950) /Argentiner idish teater. Susana Skura, Silvia Glocer (compiladoras) Buenos Aires: Editorial FFyL, UBA, 2016, 174 páginas
}

Dra. Perla Sneh

\section{(2) OpenEdition}

Journals

\section{Electronic version}

URL: http://journals.openedition.org/corpusarchivos/1770

DOI: $10.4000 /$ corpusarchivos. 1770

ISSN: 1853-8037

\section{Publisher}

Diego Escolar

\section{Electronic reference}

Dra. Perla Sneh, «Teatro ídish argentino (1930-1950) /Argentiner idish teater. Susana Skura, Silvia Glocer (compiladoras) Buenos Aires: Editorial FFyL, UBA, 2016, 174 páginas », Corpus [En línea], Vol. 7, No 1 | 2017, Publicado el 29 junio 2017, consultado el 21 abril 2019. URL : http:// journals.openedition.org/corpusarchivos/1770 ; DOI : 10.4000/corpusarchivos.1770

This text was automatically generated on 21 April 2019. 


\title{
Teatro ídish argentino (1930-1950) / Argentiner idish teater. Susana Skura, Silvia Glocer (compiladoras) Buenos Aires: Editorial FFyL, UBA, 2016, 174 páginas
}

\author{
Dra. Perla Sneh
}

1 Teatro ídish argentino (1930-1950) /Argentiner idish teater reúne trabajos realizados por un grupo de investigadores del área provenientes de distintas disciplinas: antropología, musicología, historia, lingüística, teatro y archivística. El libro es producto de dos proyectos de investigación desarrollados en el marco de la Facultad de Filosofía y Letras de la Universidad de Buenos Aires.

2 En la Argentina los estudios sobre teatro idish son recientes. Un trabajo inaugural en este sentido fue OYSFARKOYFT- Localidades Agotadas (2006) donde Silvia Hasman y Susana Skura reunieron más de cien afiches de obras realizadas en el país entre 1901 y 1930. Es, sin duda, el antecedente del libro que aquí reseñamos.

3 En el primer prólogo de Teatro idish argentino, Pablo Kohan critica con sutileza cierto afán hiperabarcativo de la actual corrección política académica para, contra ese fondo, resaltar lo específico del objeto de estudio del libro: los fenómenos musicales que podían tener lugar en el marco del teatro ídish.

Beatriz Seibel, en el segundo prólogo, aborda el contexto espectacular de los géneros musicales del teatro ídish, ubicando cómo, en el apogeo de la comedia musical en Buenos Aires a partir de 1930 (comienzo de la crisis mundial) y hasta 1935, las compañías profesionales israelitas marcan presencia en el ámbito en que el teatro de diversas colectividades despliegan sus distintos repertorios. Seibel no desatiende contradicciones como, por ejemplo, que la compañía israelita de dramas de Joseff Buloff y Luba Kadison anuncia "Crimen y castigo" en el teatro Excelsior en 1935, el mismo año en que el circo 
alemán Sarrasani (h) presta su carpa para un acto masivo del Partido Nacionalsocialista donde se jura fidelidad al Führer.

5 La Introducción -de Susana Skura y Silvia Glocer- describe el trabajo que realizan investigadores de diferentes disciplinas en torno a los géneros del teatro ídish y al impacto que provocó la llegada de músicos, actores y directores de teatro y orquesta exilados por el ascenso del nazismo. Asimismo, retoma los debates desatados con la llegada de esos artistas, debates que oponen el teatro popular versus culto y comercial vs independiente, tratando de elucidar así el papel del teatro en la cultura judía argentina. En la Introducción también puede leerse un breve recorrido contextualizador de los estudios ya realizados sobre el tema, que establecen que, en los '30-'50, Buenos Aires se consolidó como una de las capitales mundiales del teatro ídish, aunque solo recientemente se empieza a incluir el estudio de esta práctica cultural en publicaciones académicas y, más recientemente aún, en la historia del teatro en Argentina.

6 Cada autor aborda costados precisos del asunto. Susana Skura, en el primer capítulo, ("¡Gordin es mejor que Shakespeare! Mímesis de secularización en el teatro ídish") propone el concepto de mímesis de secularización como clave interpretativa del teatro ídish moderno, analizando la obra "El rey Lear judío" de Jacob Gordin (importante dramaturgo que mereció que se hablara de "la era Gordin"), donde el tragedia shakespeareana se articula con la historia de Purim y la Reina Esther. La importancia de esto reside no solo en la traducción de Shakespeare al ídish -lo que jerarquiza la lengua-, sino en la aproximación a una tradición cultural que le era ajena. La apelación a un clásico en el marco del teatro ídish e, incluso, -tal como nos informa una anécdota incluida en el texto- el recurso a la obra para dirimir un conflicto en la vida real, da cuenta de la función del teatro ídish como espacio de transmisión de mensajes morales y pedagógicos, así como su función de escenario de procesos de comunalización que se articulan en lo que Skura llama mímesis de secularización. La singularidad de la obra radica en la articulación reflexiva con los textos tradicionales que nos muestra el proceso de transculturación de una familia; en este proceso, las prácticas miméticas no son simples copias sino procesos de alterización.

7 En "Tradiciones y expectativas de los géneros y espectáculos musicales del teatro ídish", Silvia Hansman describe las características principales de los géneros musicales que habitan el teatro ídish en los años 1930-1955. Parte de una recapitulación del "teatro tradicional judío" (con sus diversas tradiciones actorales, sus características teatrales genéricas relacionadas con la farsa, la sátira y el drama y sus focos temáticos de historias bíblicas o historias de fugitivos y contrabandistas entre otros motivos) para diferenciarlo del teatro ídish moderno, surgido en Europa Oriental a mediados del siglo XIX y que incorpora no sólo textos teatrales ligados a la literatura y a sus géneros modernos, sino también nuevos ámbitos de interpretación (bares, salas), así como nuevas tradiciones actorales inspiradas en el arte ruso. En este sentido, el teatro ídish moderno es un teatro secular, siendo su manifestación inaugural el teatro de operetas de Abraham Goldfaden, cuyas características enumera como parte de lo que denomina "mito fundacional". Sin embargo, Hansman se propone mostrar que ya en el siglo XIX existían artistas que actuaban en ámbitos seculares y asumían una identidad distintiva sin relación con la opereta moderna. Estos eran los así llamados Broder Zingers -"cantantes de la ciudad de Brod o Brody"-. Hansman enumera también las características de estos actores y luego repasa y describe los géneros teatrales escritos o presentado en el teatro ídish de Argentina en los años ‘ 30 , ‘ 40 y ‘ 50 , entre los que se cuentan las operetas, los melodramas, 
las comedias musicales, las revistas, el café-concert, el drama y otro tipo de espectáculos (galas, programas, radio teatro homenajes y piezas o shtikn).

En el capítulo siguiente, Hansman y Skura unen esfuerzos para abordar la legitimización del repertorio del teatro ídish argentino en los años 1930-1955, considerando las obras que lo integraban, deteniéndose específicamente en tres de ellas: 1) Buitre de Moyshe Kulbak, publicada en Moscú, en 1936 y presentada en 1938 (teatro IFT/Lasalle), que trata sobre la conscripción forzada de niños judíos al ejército del Zar Nicolás II, donde se los retenía con métodos violentos y se los bautizaba a la fuerza. El texto es costumbrista con elementos pre-modernos de la cultura rural judía y presenta a un héroe trágico muy alejado del héroe de la literatura revolucionaria. 2) "La gran ciudad" (Teatro Ombú 1938), de Misha Straitman, una opereta costumbrista con cierta complejidad argumental (inversión de roles de género tradicionales) y final feliz que muestra el triunfo del teatro sobre la cultura prostibularia (que dominaba anteriormente el ámbito) mostrando que la producción local no solo era posible sino que podía alcanzar niveles de excelencia. 3) "El cantor genio", (Excelsior, 1942), leyenda popular adaptada al teatro sobre un personaje semi-histórico de mediados del siglo XIX, un cantor litúrgico judío que atraviesa un conflicto espiritual y social al entrar en contacto con el mundo del arte polaco, es decir, con una cultura donde la música funciona como instrumento de conformación del incipiente estado-nación. Con estas obras, Hansman y Skura trabajan sobre la noción de legitimización en relación a los diversos espacios y modos de instalarla (revistas, anuarios, crítica, afiches, etc.).

En "Jacobo Ficher: Fragmentos musicales olvidados", Silvia Glocer aborda la incursión por los teatros judíos y las radios de Buenos Aires del conocido compositor de la música académica argentina Jacobo Ficher (Fijer), aspecto desatendido por sus biógrafos. Glocer también aborda -en "Músicos exiliados por causa del nazismo en el teatro ídish de Buenos Aires"- la historia de los músicos que debieron huir del Tercer Reich y que, a su llegada a Buenos Aires, comenzaron a participar en el teatro ídish. Más de ciento veinte de ellos llegaron a Argentina, contando la mayoría con una vida profesional destacada en Europa. Algunos se dedicaron a las operetas y demás géneros musicales del teatro ídish, provocando en él un fuerte impacto cualitativo y cuantitativo. Su llegada alborotó el mapa musical de Buenos Aires, observándose un incremento en las puestas de operetas y en la frecuencia de las mismas, así como una diversificación en los géneros musicales ya que se incorporan al repertorio melodramas, café-concerts, etc. En esos años (1939-1943) el teatro ídish recupera el esplendor de los años '20, interrumpido por la crisis del '30. El trabajo también ofrece una apretada pero medulosa síntesis biográfica sobre algunos de los músicos que integran este grupo.

En "Juegos de lenguaje/Juegos por dinero en tres canciones de Max Perlman", Susana Skura y Lucas Fiszman abordan los juegos lingüísticos en ciertas canciones de un personaje muy popular del teatro ídish, Max Perlman, cuya obra es tomada por primera vez como objeto de estudio académico. En estas canciones, a pesar de su estilo considerado "chabacano"- los autores encuentran elementos discursivos y lingüísticos amén de referencias a la vida cotidiana judía argentina- relevantes para ejemplificar el contacto entre lenguas y la competencia multilingüística y sociocultural de una figura cultural de ese período. Las canciones se refieren al juego como actividad novedosa y significativa. Los autores sostienen que la producción de Perlman indexicaliza un momento de transición socioeconómica y lingüística, detectando en sus creaciones diversos grados de incorporación del castellano al ídish y también, diversos modos de 
parodiar la competencia comunicativa que exigen las nuevas situaciones sociales de sus oyentes. La fuerte interpelación por medio del humor opera como comentario metalingüístico, jugando con las diferentes prácticas de lenguaje en las que su público se reconoce. Esto también se inscribe en la clave de interpretación propuesta anteriormente, definida como mímesis de secularización.

Paula Ansaldo cierra el libro con un texto sobre el teatro como escuela para adultos, recorriendo la historia del IFT (Ídisher Folks Teater, Teatro Popular Judío) -nacido con el nombre de IDRAMST (Idishe Dramatihe Stude)-, como expresión del teatro independiente dentro del teatro judío, en su tránsito de la lengua ídish al español en los años 1932-1957. Ansaldo establece cómo el teatro independiente judeoargentino surge en oposición a la producción comercial predominante por entonces. Ubica diversos momentos: la fundación del sindicato de actores judíos (Actiorn Farein) en 1922, la fundación del grupo teatral Jung Argentine en 1928 y la creación del IFT en 1932. Se diferenciará del teatro empresarial por su contenido político y su consideración del arte como herramienta de transformación social en línea con las ideas de Romain Rolland y de I. L. Peretz, una de cuyas frases estaba inscripta en una pared del IFT: el teatro es la escuela para los adultos. A partir de 1941, el IFT pasó a formar parte del ICUF (Idisher Cultur Farband o Federación Cultural Judía). En 1946, pudo construirse el propio edificio que aún hoy existe. Ansaldo dedica especial atención al abandono del ídish para pasar a montar obras en castellano, pasaje que significó un parteaguas en la vida del IFT. El punto de inflexión se dio en 1957, con la puesta de "El diario de Ana Frank". Así, los integrantes del IFT priorizaron el contenido por sobre la forma de transmitirlo y los contenidos judíos ya no son considerados como indisolublemente unidos a la lengua.

En resumen, estamos ante una investigación relevante y cuidadosa en la aplicación de diferentes dimensiones y metodologías de análisis para el abordaje de materiales y personajes poco tematizados en los marcos académicos y con una visión compartida del teatro como fenómeno social, como espacio de creación y sostén de lazos comunitarios, de procesos identitarios, culturales y lingüísticos.

\section{AUTHOR}

\section{DRA. PERLA SNEH}

Universidad Nacional de Tres de Febrero

Correo electrónico: psneh@untref.edu.ar 